Department of Population Studies, London School of Hygiene and Tropical Medicine, London, UK; ${ }^{3}$ University of Washington, Seattle, Washington State, USA

Objective The objective of this paper is to examine the association between marital status and the risk of HIV infection in the informal settlements of Nairobi. The findings from this study will inform HIV prevention programs, particularly among poor and marginalised groups in the informal settlements.

Methods Data are derived from a cross-sectional population-based survey nested in an ongoing Demographic Surveillance System (DSS) in two urban informal settlements in Nairobi city, where a total of about 60000 individuals living 23000 households are under surveillance. Descriptive statistics and multivariate logistic regression analysis were used to describe the characteristics of the sample, as well as to assess the association between marital status and risk of HIV infection.

Results The HIV prevalence of respondents who were divorced, separated or widowed was $27 \%$, among those who were married was $12 \%$, and among those who were never married was $5 \%$. Married respondents $(\mathrm{OR}=1.78$; $\mathrm{p}$ value $<0.05)$ and those who were divorced, separated or widowed $(\mathrm{OR}=4.06$; $\mathrm{p}$ value $<0.001)$ were significantly more likely to be infected with HIV compared to respondents who were never married. Circumcision was also a significant predictor of HIV infection. Men who were circumcised $(\mathrm{OR}=0.36$; $\mathrm{p}$ value $<0.05)$ were less likely to be HIV positive compared to those who were not circumcised.

Conclusion There is need for HIV prevention interventions to adopt a more targeted approach, particularly with regard to designing and implementing programs geared towards addressing the increased risk of HIV infection among married people and those who were formerly married.

\section{P2-432 PATTERNS AND DETERMINANTS OF BREASTFEEDING AND COMPLEMENTARY FEEDING PRACTICES IN URBAN INFORMAL SETTLEMENTS, NAIROBI, KENYA}

doi:10.1136/jech.2011.142976l.62

${ }^{1} \mathrm{E}$ Kimani-Murage, ${ }^{2} \mathrm{~N}$ Madise, ${ }^{1} \mathrm{~J}-\mathrm{C}$ Fotso, ${ }^{1} \mathrm{C}$ Kyobutungi, ${ }^{*} \mathrm{M}$ Kavao, ${ }^{3} \mathrm{~T}$ Gitau, ${ }^{1} \mathrm{~N}$ Yatich. ${ }^{1}$ African Population and Health Research Center, Nairobi, Kenya; ${ }^{2}$ University of Southampton, Southampton, UK; ${ }^{3}$ University of the Witwatersrand, Johannesburg, South Africa

Introduction Little evidence exists on breastfeeding and infant feeding practices in urban slums in sub-Saharan Africa. Our aim was to assess breastfeeding and infant feeding practices in Nairobi slums with reference to WHO recommendations.

Methods Data from a longitudinal study conducted in two Nairobi slums are used. The study involves 4299 children aged 0-42 months, born between September 2006 and January 2010, for the period they were infants. All women who gave birth during this period were interviewed on breastfeeding and complementary feeding practices at recruitment and this information was updated twice, at 4-monthly intervals. Cox proportional hazard analysis was used to determine factors associated with cessation of breastfeeding in infancy and early introduction of complementary foods.

Results There was universal breastfeeding with almost all children (99.0\%) having ever been breastfed, and $85 \%$ were still breastfeeding by the end of the $11^{\text {th }}$ month. Exclusive breastfeeding for the first 6 months was rare (2\%). Factors associated with sub-optimal infant breastfeeding and feeding practices in these settings include child's sex; perceived size at birth; mother's marital status, ethnicity, and education level; pregnancy desirability; place of delivery; and slum of residence.

Conclusions The study indicates poor adherence to WHO recommendations for breastfeeding and infant feeding practices. Breastfeeding and infant feeding patterns are associated with child, maternal and household level characteristics. Interventions and further research should pay attention to factors such as cultural practices, access to and utilisation of healthcare facilities, child feeding education, and family planning.

\section{P2-433 NUTRITIONAL SUPPLEMENTATION IN EARLY LIFE AND FUTURE RISK OF OBESITY: LONG-TERM FOLLOW-UP OF THE HYDERABAD NUTRITION TRIAL}

doi:10.1136/jech.2011.142976l.63

${ }^{1} \mathrm{~S}$ Kinra, ${ }^{*} \mathrm{H}$ Kuper, ${ }^{2} \mathrm{~K}$ V R Krishna, ${ }^{3} \mathrm{~A}$ Taylor, ${ }^{2} \mathrm{~B}$ Kulkarni, ${ }^{3} \mathrm{Y}$ Ben-Shlomo, ${ }^{3} \mathrm{G}$ D Smith, ${ }^{1} \mathrm{~S}$ Ebrahim. ${ }^{1}$ London School of Hygiene \& Tropical Medicine, London, UK; ${ }^{2}$ National Institute of Nutrition, Hyderabad, India; ${ }^{3}$ University of Bristol Department of Social Medicine, Bristol, UK

Introduction Nutritional supplementation programmes for pregnant women and young children exist in much of the developing world, but their long term health consequences, particularly in the context of nutrition transition, are unknown.

Methods The Hyderabad Nutrition Trial was a community trial to evaluate a supplemental nutrition programme for pregnant women and young children ( $<6$ years), conducted in 29 villages (15 intervention, 14 control) near Hyderabad city in India during 1987-1990. The supplement was a cereal based meal providing $2 \mathrm{MJ}$ calories and $20 \mathrm{~g}$ protein per day. Children born during the trial period were reexamined $\sim 20$ years later, and adiposity was assessed by DXA scans.

Results We recruited 1120 participants (27\% female) aged 18-21 years: 581 intervention and 539 controls. The body mass index of the intervention and control participants was similar $\left(19.3 \mathrm{~kg} / \mathrm{m}^{2}\right)$. There was some indication of greater adiposity in the intervention arm participants, but these differences were broadly consistent with chance. The total body fat (geometric mean) was $18.0 \%$ in the intervention arm, compared to $17.1 \%$ in the control arm (ratio: $1.04 ; 95 \%$ CI 0.99 to 1.09). The intervention and control arms had similar levels of central adiposity (8.5\% of the total body fat was in the L1L4 region).

Conclusion In this sample of rural Indians, modest protein-calorie supplementation in early life on the whole was not associated with greater total or central adiposity in young adulthood. Whether stronger differences emerge with age or progression of nutrition transition remains to be established.

\section{P2-434 TRENDS AND EPIDEMIOLOGIC FEATURES OF TUBERCULOSIS IN THE WEST AZERBAIJAN PROVINCE OF IRAN, 2004-2009}

doi:10.1136/jech.2011.142976l.64

${ }^{1}$ G Kolifarhood, ${ }^{*}$ S Dastgiri, ${ }^{3,4}$ S Salarilak, ${ }^{1} \mathrm{~N}$ Khosravi, ${ }^{4} \mathrm{~A} N$ Nejad, ${ }^{4} \mathrm{D}$ Khorasani, ${ }^{4} \mathrm{~B}$ Neamati, ${ }^{4} \mathrm{~A}$ Yousefzade, ${ }^{4} \mathrm{P}$ Mikaili, ${ }^{4} \mathrm{Y}$ Mohammadpour, ${ }^{4} \mathrm{R}$ Ghareaghaji. ${ }^{1}$ Zanjan University of Medical Science, Zanjan, Iran; ${ }^{2}$ Tabriz University of Medical Science, East Azerbaijan, Iran; ${ }^{3}$ slamic Azad Univrsity of Iran, Tabriz Branch, Medical Faculty, Tabriz, Iran; ${ }^{4}$ Urmia University of Medical Science, West Azerbaijan, Iran

Objective To determine of epidemiologic patterns and recent trends of pulmonary and extrapulmonary tuberculosis in West Azerbaijan province of Iran, during 2004-2009.

Material and Methods In this cross-sectional study, we studied the data of 1323 TB new cases that have been recorded by TB Management Center of Vice-chancellor of health affairs in West Azerbaijan province of Iran. National census data of 2006 were used for determining the incidence rates. Cochran-Armitage test was used to analyse the incidence trends.

Results The incidence rate of tuberculosis at this province was declined from 10.16 to 7.85 per 100000 during 2004-2009. Despite of higher incidence rates in southern regions, its two districts 